\title{
Health-related quality of life in diabetic patients and controls without diabetes in refugee camps in the Gaza strip: a cross-sectional study
}

\author{
Ashraf Eljedi ${ }^{\dagger 1}$, Rafael T Mikolajczyk* ${ }^{*}$, Alexander Kraemer ${ }^{2}$ and \\ Ulrich Laaser ${ }^{3}$
}

\begin{abstract}
Address: ${ }^{1}$ Faculty of Nursing, The Islamic University of Gaza, Gaza strip, Palestinian Territories, ${ }^{2}$ Department of Public Health Medicine, School of Public Health, University of Bielefeld, Bielefeld, Germany and ${ }^{3}$ Department of Epidemiology and International Public Health, School of Public Health, University of Bielefeld, Bielefeld, Germany
\end{abstract}

Email: Ashraf Eljedi - aajedi19772@hotmail.com; Rafael T Mikolajczyk* -rmikolajczyk@uni-bielefeld.de; Alexander Kraemer - alexander.kraemer@uni-bielefeld.de; Ulrich Laaser - ulrich.laaser@uni-bielefeld.de

* Corresponding author †Equal contributors

Published: 30 October 2006

BMC Public Health 2006, 6:268 doi:10.1 186/147|-2458-6-268

This article is available from: http://www.biomedcentral.com/I47I-2458/6/268

(C) 2006 Eljedi et al; licensee BioMed Central Ltd.

This is an Open Access article distributed under the terms of the Creative Commons Attribution License (http://creativecommons.org/licenses/by/2.0), which permits unrestricted use, distribution, and reproduction in any medium, provided the original work is properly cited.
Received: 20 April 2006

Accepted: 30 October 2006

\begin{abstract}
Background: Prevalence of diabetes mellitus is increasing in developed and developing countries. Diabetes is known to strongly affect the health-related quality of life (HRQOL). HRQOL is also influenced by living conditions. We analysed the effects of having diabetes on HRQOL under the living conditions in refugee camps in the Gaza strip.
\end{abstract}

Methods: We studied a sample of 197 diabetic patients who were recruited from three refugee camps in the Gaza strip and 197 age- and sex-matched controls living in the same camps. To assess HRQOL, we used the World Health Organization Quality of Life questionnaire (WHOQOL-BREF) including four domains (physical health, psychological, social relations and environment). Domain scores were compared for cases (diabetic patients) and controls (persons without diabetes) and the impact of socio-economic factors was evaluated in both groups.

Results: All domains were strongly reduced in diabetic patients as compared to controls, with stronger effects in physical health (36.7 vs. 75.9 points of the $0-100$ score) and psychological domains (34.8 vs. 70.0$)$ and weaker effects in social relationships (52.4 vs. 7I.4) and environment domains (23.4 vs. 36.2). The impact of diabetes on HRQOL was especially severe among females and older subjects (above 50 years). Low socioeconomic status had a strong negative impact on HRQOL in the younger age group ( $<50$ years).

Conclusion: HRQOL is strongly reduced in diabetic patients living in refugee camps in the Gaza strip. Women and older patients are especially affected.

\section{Background}

Diabetes mellitus is a serious disease and a cause for a growing public health concern in both developed and developing countries. Globally, the number of people with diabetes is expected to double between 2000 and 2030 while public awareness about this disease remains low $[1,2]$. Several studies have demonstrated that diabetes has a strong negative impact on the health-related quality 
of life (HRQOL), especially in the presence of complications [3-9]. However, most of the studies on diabetes and HRQOL have been conducted in developed countries (review in [10]) and studies of the HRQOL in diabetic patients in developing countries are rare [11-14].

In the Gaza strip, more than one third of the Palestinian population lives in eight very densely populated camps [15]. The prevalence of diabetes was estimated at $11 \%$ in the rural and $14 \%$ in the urban population of the WestBank [16]. The prevalence of complications of diabetes in this population is high [17] and complications of diabetes are known to negatively affect the HRQOL of diabetic patients. In an Iranian randomized trial a health education programme considerably improved the HRQOL of diabetic patients in the intervention group [14]. However, because of the lack of controls without diabetes living under the same conditions, the authors were not able to assess to which extent the intervention reduced the gap between diabetic patients and healthy controls. In a population-based Dutch study diabetic patients without complications had only slightly lower HRQOL than age matched persons in the general population [4]. However, the effects of socio-economic differences may be weaker in developed countries than in conditions of poverty in developing countries. The negative impact of socio-economic conditions on HRQOL among diabetic patients can be even stronger in refugees. The aim of our study was to examine the HRQOL of diabetic patients in a large and long-term refugee community in camps in the Gaza strip in comparison to controls living in similar conditions. We focussed on the question whether variables potentially affecting HRQOL in healthy controls have a different impact in diabetic patients. The secondary aim of the analysis was to evaluate the psychometric properties of the Arabic version of a HRQOL instrument.

\section{Methods \\ Sample}

For the purpose of comparison we aimed at recruiting about 200 patients with diabetes and 200 controls without diabetes living in the camps in the Gaza strip. We started with diabetic refugees who were randomly selected from the files in "United Nations Relief and Works Agency for Palestine" clinics (UNRWA) in the biggest three refugee camps in the Gaza strip: Jabalia in the North, Nuseirat in the Middle, and Rafah in the South. The sample obtained at each site was proportional to the population living in the respective regions. Inclusion criteria for patients were: being a resident of one of the three refugee camps, a diagnosis of type 1 or type 2 diabetes with treatment initiated at least six months prior to the study. Exclusion criteria were having any co-morbidities (any chronic disease not clearly related to diabetes, patients with complications of diabetes were not excluded) and pregnancy at the time of the survey. The distinction between co-morbidities and complications of diabetes was based on medical records of the patient. Diabetes was diagnosed according to any one of the following criteria: (1) symptoms of diabetes and random plasma glucose concentration $\geq 200 \mathrm{mg} / \mathrm{dl}(11.1 \mathrm{mmol} / \mathrm{l})$, (2) fasting plasma glucose $\geq 126 \mathrm{mg} / \mathrm{dl}$ (7.0 mmol/l), (3) 2-hours plasma glucose $\geq 200 \mathrm{mg} / \mathrm{dl}(11.1 \mathrm{mmol} / \mathrm{l})$ during an oral glucose tolerance test.

The first 20 patients were recruited for pilot-testing the survey and were therefore excluded from the main study. Of the following 299 patients with diabetes, 67 suffered from other diseases and 7 were pregnant, leaving 225 eligible patients for participation. 28 patients refused to participate, resulting in a final sample of 197 (response rate of $88 \%$ ). Through referrals by diabetic patients we recruited 197 refugees without diabetes or any other chronic disease living in the same camps that were matched to patients by age groups and gender. For logistic reasons the number of controls refusing participation could not be obtained. All participants were asked to complete a self-administered questionnaire. Data were collected from November 2003 to December 2004. Written informed consent was obtained from all participants. The study was approved by the Ministry of Health and the United Nations Health Office in the Gaza strip.

\section{Questionnaire}

We used the World Health Organization Quality of Life Questionnaire - short version (WHOQOL-BREF) to assess quality of life $[18,19]$. This questionnaire was developed with 15 international field centres to obtain an assessment tool that is applicable cross-culturally. It was used in 212 publications currently referenced in Medline (search term: "WHOQOL", April 2006), 4 of them dealing with diabetic patients (search term: "WHOQOL diabetes"). The four domains of the WHOQOL-BREF are physical health, psychological (e.g. self-esteem), social relationships (e.g. social support) and environment (e.g. freedom, physical safety). Subjects rated all items on a 5 point Likert-type scale. The questionnaire was translated into Arabic language using two independent translations from English to Arabic. The translations were reviewed by the first author (A.E.) and synthesised into one version. This preliminary Arabic questionnaire was back-translated into English by two independent translators. Both versions were compared and the Arabic version was revised where necessary.

Raw scores for the domains of WHOQOL-BREF were calculated by adding values of single items and were transformed on the scale ranging from 0 to 100 , where 100 is the highest and 0 the lowest HRQOL [20]. Additionally to the variables used for matching (gender, age and place of 
residence) we also collected some limited socio-demographic (marital status, education, own housing versus rental, occupational status) and disease related information (type of diabetes, duration of diabetes since the first diagnosis, medication for diabetes, complications of diabetes).

\section{Statistical analysis}

We evaluated the psychometric characteristics of the Arabic translation of WHOQOL-BREF in the sample by means of internal reliability (Cronbach's alpha). We used the chi-square test for comparison of categorical variables and the t-test for the comparison of mean score values for the domains of WHOQOL-BREF between groups. Further, we performed multivariate analysis of variance to analyse the determinants of HRQOL in both groups. All independent variables were dichotomised. We followed standard recommendations by Hosmer and Lemeshow for model-building strategies [21]. Since most of the variables had a significant interaction with the age and case-control status including them all jointly in the model would yield too many variables per observation. We therefore included interactions in two separate sets: interactions between case-control status and all other variables and interactions between age groups and all other variables. From each set we eliminated interactions which did not cross the significance level of 0.1 . Finally, we included all interactions from the previous step in the model and eliminated stepwise all terms which were not significant on the 0.05 level. Based on the final model we calculated the contribution of interactions to the HRQOL with Waldtype confidence intervals, comparing to a single reference category for all strata. All analyses were performed with SPSS $^{\circledast}$ for Windows version 12 , for the analysis of variance we used the GLM procedure and obtained the significance statistics from multivariate tests including all domains using the Pillai-Spur criterion. The choice of multivariate technique was motivated by a potential correlation of domain scores within the respondents and had the benefit of a homogenous set of independent variables in the models for all outcomes despite using variable selection. The interpretation of the results is based on a clinically meaningful difference of 5 points of the $0-100$ scores.

\section{Results \\ Psychometric characteristics of the WHOQOL-BREF in the study sample}

The internal reliability was very high for three domains and reasonably high for the fourth one. Cronbach's alpha for the physical health domain was 0.95 , for the psychological domain 0.94 , for social relationships domain 0.6 and 0.85 for the environment domain. For the physical health, psychological and environment domains, the internal reliabilities could not be improved through removing any of the items. In the social relationships domain, the item related to sexual life satisfaction had a considerably lower mean than the remaining items: personal relationships and support from friends. Removing this item from the scale would increase internal reliability. In the analysis stratified by gender this observation persisted, however, stratifying by case-control status (diabetes versus non-diabetes) this was true only for diabetic patients. For the purpose of standardisation we used the instrument as given and did not remove the sexual life satisfaction item from the social relationships domain.

\section{Characteristics of the sample}

Socio-economic information for the two groups is presented in Table 1. Patients with diabetes were more often widowed, had lower levels of education and income, but were more often employed than non-diabetic controls. They were mostly patients with type 2 diabetes (92.4\%) with a relatively long history of disease $(72.6 \%$ over 6 years, 33.5\% over 10 years). Despite the high proportion of patients with complications $(80.2 \%$ with one or more self-reported major complication: nephropathy, neuropathy, retinopathy or diabetic foot), more than half were treated by oral medication $(53.8 \%)$. Female patients had a longer duration of the disease and more self-reported complications than male patients (Table 2).

\section{Evaluation of the HRQOL}

The HRQOL was significantly lower for diabetic patients than for controls in all of the domains with the largest differences in the physical health and psychological domains (39 and 35 points difference) and smaller differences in social relationships and environment domains (19 and 13 points difference) (Table 3 ). Both groups had particularly low scores in the environmental domain with the smallest difference between groups, indicating the bad environmental conditions affecting HRQOL of diabetic patients and controls in a similar way.

In the multivariate analysis (joint analysis for all domains) several interactions including group status (diabetic patients vs. controls) and age were significant ( $\mathrm{p}<$ 0.05 ) (Table 4). Female diabetic patients had consistently lower HRQOL for all domains than male diabetic patients, whereas the gender difference in controls was negligible. For example healthy women reported a 0.5 point better score in the physical health domain, but women with diabetes a $9.1(-45.2-(-36.1)=9.1)$ point lower score. Similarly, diabetic patients younger than 50 years had a considerably better HRQOL than older patients, whereas the age effect in controls was very small. Diabetic patients with a lower number of persons financially depending on them had a decreased HRQOL, but non-diabetic patients with a lower number of persons financially depending on them had a slightly increased HRQOL. Lower income (below 200 \$) had stronger effect 
Table I: Socio-economic characteristics of the sample (\%)

\begin{tabular}{|c|c|c|c|}
\hline Characteristic & Diabetic refugees $N=197$ & Non-diabetic refugees $N=197$ & $\mathrm{p}$-value Chi-square \\
\hline \multicolumn{4}{|l|}{ Matching factors } \\
\hline Gender & & & - \\
\hline Male & 52.8 & 52.8 & \\
\hline Female & 47.2 & 47.2 & \\
\hline Age groups & & & - \\
\hline$<30$ & 6.1 & 6.1 & \\
\hline $30-39$ & 10.7 & 10.7 & \\
\hline $40-49$ & 24.9 & 24.9 & \\
\hline $50-60$ & 33.5 & 33.5 & \\
\hline$>60$ & 24.9 & 24.9 & \\
\hline \multicolumn{4}{|l|}{ Other variables } \\
\hline Education & & & $<0.001$ \\
\hline None & 28.4 & 4.1 & \\
\hline Primary & 14.7 & 4.11 & \\
\hline Secondary & 15.2 & 13.7 & \\
\hline Tertiary & 20.3 & 35.0 & \\
\hline Higher & 21.3 & 43.1 & \\
\hline Marital status & & & 0.001 \\
\hline Single & 7.1 & 8.6 & \\
\hline Married & 76.6 & 87.3 & \\
\hline Widowed & 17.7 & 3.6 & \\
\hline Divorced & 1.5 & 0.5 & \\
\hline House type & & & 0.26 \\
\hline Owned & 69.5 & 68.5 & \\
\hline Refugee shelter* & 24.5 & 22.3 & \\
\hline Rented & 5.1 & 9.1 & \\
\hline Monthly Income & & & 0.001 \\
\hline Below 200 US\$ & 65.5 & 50.8 & \\
\hline $200-500$ US\$ & 24.9 & 42.1 & \\
\hline$>500$ US\$ & 9.6 & 7.1 & \\
\hline Employment & & & $<0.001$ \\
\hline No & 59.4 & 66.5 & \\
\hline Yes & 40.6 & 33.5 & \\
\hline Number of people financially depending on the respondent & & & 0.003 \\
\hline $0-5$ & 58.9 & 61.9 & \\
\hline $6-10$ & 38.1 & 27.4 & \\
\hline$>10$ & 3.0 & 10.7 & \\
\hline
\end{tabular}

* The temporary houses built by the United Nations Relief and Works Agency for Palestinian Refugees in the Near East (UNRWA) in I948 as the first shelter.

on HRQOL among patients younger than 50 than for older patients. In the age group below 50 years, being in the category with lowest income was comparable to having diabetes in terms of impact on physical health and psychological domain. The socio-economic status had even a higher impact on social relationships and environment domain in this comparison. Being married had a small positive effect on HRQOL.

\section{Discussion}

We analysed the HRQOL in a sample of diabetic patients living in refugee camps in the Gaza strip in comparison to gender- and age-matched non-diabetic controls from the same camps. Diabetes and its complications affected negatively all of the domains of the WHOQOL-BREF, how- ever the effects were strongest for the physical health and psychological domains and weaker for the social relationships and environment domains. We found a strong effect of interactions between gender and disease status (diabetic patients vs. controls). Whereas this finding could be partly explained by the worse situation of female patients in respect to the disease in our sample, this is still an evidence for gender inequalities. Similar difference in HRQOL of both genders was observed in a study conducted in Iran [13]. Lower HRQOL in women with diabetes was also reported in other studies [4,5]. Age strongly affected the HRQOL of diabetic patients in physical health and psychological domains and had almost no effects on HRQOL among controls. Had we not taken into account the interactions, we would have found mistakenly that 
Table 2: Characteristics of the diabetes patients (\%)

\begin{tabular}{|c|c|c|c|}
\hline Characteristics & Male $\mathrm{N}=104$ & Female $\mathrm{N}=93$ & $\mathrm{p}$-value Chi-square \\
\hline Type of diabetes & & & 0.75 \\
\hline Type I & 7.2 & 8.1 & \\
\hline Type 2 & 92.8 & 91.9 & \\
\hline Duration of diabetes (since first diagnosis) & & & 0.23 \\
\hline$<$ I year & 8.2 & 3.8 & \\
\hline $2-5$ years & 34.1 & 31.7 & \\
\hline $6-10$ years & 33.7 & 39.8 & \\
\hline$>10$ years & 24.0 & 24.7 & \\
\hline Complications & & & $<0.001$ \\
\hline None & 58.7 & 30.1 & \\
\hline \multicolumn{4}{|l|}{ Major one } \\
\hline Retinopathy & 10.6 & 17.7 & \\
\hline Nephropathy & 3.8 & 9.7 & \\
\hline Neuropathy & 4.3 & 9.7 & \\
\hline Diabetic foot & 4.8 & 12.9 & \\
\hline Two or more & 17.8 & 19.9 & \\
\hline Treatment for diabetes & & & 0.014 \\
\hline Pills & 54.8 & 51.1 & \\
\hline Insulin & 15.9 & 18.8 & \\
\hline Pills + Insulin & 16.8 & 25.3 & \\
\hline Diet only & 12.5 & 4.8 & \\
\hline
\end{tabular}

these factors also severely impact HRQOL among controls. Interestingly, in the analysed set of variables, education played no independent role with respect to HRQOL. Another important finding is the high impact of the economic situation on the HRQOL (which did not interact with the disease status), especially in the younger age group. This is a big concern, because more than one half of the sample had an income in the lowest category.

This study also contributed to the literature by translating the WHOQOL-BREF into Arabic and by administering the assessment tool for the first time to an Arabic speaking sample. The psychometric properties of the Arabic translation of the WHOQOL-BREF were somewhat better than in a Norwegian general population sample [22] or Danish sample consisting of five different groups of patients [23], but this may be due to the fact that our sample was more homogenous.

Table 3: Crude domain scores of WHOQOL-BREF for diabetic patients and controls (mean scores and $95 \%$ confidence intervals)

\begin{tabular}{lcc}
\hline Domain & Diabetes patients & controls \\
\hline Physical health & $36.7(33.7 ; 39.6)$ & $75.9(73.0 ; 78.8)$ \\
Psychological & $34.8(31.8 ; 37.8)$ & $70.0(66.7 ; 72.7)$ \\
Social relationships & $52.4(49.7 ; 55.1)$ & $71.4(68.7 ; 74.1)$ \\
Environment & $23.4(21.0 ; 25.9)$ & $36.2(33.7 ; 38.6)$ \\
\hline
\end{tabular}

The strengths of this study are the relatively large sample size and inclusion of a control group. Further, the sample was designed to represent the refugee population in the Gaza strip camps, a population which is not only underserved but also understudied. There are however several weaknesses of this study. Diabetic patients recruited for this study are a random sub-sample of patients treated in the UNRWA clinics but may not represent all diabetic patients living in the camps. Whereas this restriction does not threaten the internal validity of the analysis, findings may be not generalisable. The Palestinian Health care system comprises three sectors: the governmental, UNRWA, and the private sector. Most of the refugees in the camps receive care from the UNRWA, but some of the refugees are able to pay for the health insurance and they prefer to seek health care from the governmental institutions because of their comprehensiveness. Other refugees receive health care from the private sector outside of the camps. Patients treated at the UNRWA clinics may have a worse health condition than patients receiving care from other providers. In some cases the medical records regarding complications of diabetes may have been incomplete. This information was not verified by an examination by the physician for the purpose of this study. This may have resulted in underreporting of complications, but this does not affect the comparison between diabetic patients and controls.

We do not know whether the controls proposed by the patients had any characteristics which were related to either higher or lower HRQOL than in the general popu- 
Table 4: Differences in domain scores associated with determinants of HRQOL (negative numbers mean reduction of HRQOL, positive numbers an improvement in comparison to the references group, adjusted for all other variables in the table, presented is mean difference and its $\mathbf{9 5 \%}$ confidence interval, all included interactions were significant at the level of $p<0.05$ in multivariate evaluation)

\begin{tabular}{|c|c|c|c|c|}
\hline & Physical health & Psychological & Social relationships & Environment \\
\hline \multicolumn{5}{|l|}{ Effect modification by diabetes } \\
\hline \multicolumn{5}{|l|}{ Diabetes patients } \\
\hline Male & $-36.1(-47.0 ;-25.3)$ & $-31.8(-42.7 ;-20.9)$ & $-14.2(-24.9 ;-3.5)$ & $-1.7(-11.3 ; 7.9)$ \\
\hline Female & $-45.2(-53.4 ;-37.0)$ & $-45.4(-53.7 ;-37.2)$ & $-19.5(-27.6 ;-11.5)$ & $-12.3(-19.6 ;-5.1)$ \\
\hline \multicolumn{5}{|l|}{ Controls } \\
\hline Male & $-0.5(-5.7 ; 4.7)$ & $-2.0(-7.2 ; 3.2)$ & $-1.6(-12.7 ;-3.4)$ & $-1.4(-6.0 ; 3.2)$ \\
\hline Female & Reference & Reference & Reference & Reference \\
\hline \multicolumn{5}{|l|}{ Diabetes patients } \\
\hline Age below 50 & $-26.4(-37.2 ;-15.6)$ & $-24.9(-35.8 ;-14.1)$ & $-8.7(-19.4 ; 1.9)$ & $-6.8(-16.4 ; 2.7)$ \\
\hline 50 or more & $-45.2(-53.4 ;-37.0)$ & $-45.4(-53.7 ;-37.2)$ & $-19.5(-27.6 ;-11.5)$ & $-12.3(-19.6 ;-5.1)$ \\
\hline \multicolumn{5}{|l|}{ Controls } \\
\hline Age below 50 & $-2.2(-9.5 ; 5.1)$ & $-3.5(-10.9 ; 3.8)$ & $-5.3(-12.5 ; 1.9)$ & $3.1(-3.3 ; 9.6)$ \\
\hline 50 or more & Reference & Reference & Reference & Reference \\
\hline \multicolumn{5}{|l|}{ Diabetes patients } \\
\hline 5 or less depending persons & $-53.8(-64.8 ;-42.8)$ & $-51.4(-62.4 ;-40.3)$ & $-28.9(-39.7 ;-18.1)$ & $-23.3(-33.1 ;-13.6)$ \\
\hline 6 or more & $-45.2(-53.4 ;-37.0)$ & $-45.4(-53.7 ;-37.2)$ & $-19.5(-27.6 ;-11.5)$ & $-12.3(-19.6 ;-5.1)$ \\
\hline \multicolumn{5}{|l|}{ Controls } \\
\hline 5 or less depending persons & $4.8(-1.5 ; 11.1)$ & $6.7(0.4 ; 13.0)$ & $4.0(-2.2 ; 10.2)$ & II.7 (6.1; I7.2) \\
\hline 6 or more & Reference & Reference & Reference & Reference \\
\hline \multicolumn{5}{|l|}{ Other variables } \\
\hline \multicolumn{5}{|l|}{ Younger refugees (age below 50) } \\
\hline Income below 200 & $-21.5(-30.2 ;-12.8)$ & $-23.4(-32.1 ;-14.7)$ & $-15.7(-24.3 ;-7.2)$ & $-16.1(-23.7 ;-8.4)$ \\
\hline Income above 200 & $-2.2(-9.5 ; 5.1)$ & $-3.5(-10.9 ; 3.8)$ & $-5.3(-12.5 ; 1.9)$ & $3.1(-3.3 ; 9.6)$ \\
\hline \multicolumn{5}{|c|}{ Older refugees (age of 50 or more) } \\
\hline Income below 200 & $-10.4(-15.3 ;-5.5)$ & $-8.9(-13.8 ;-4.0)$ & $-5.5(-10.3 ;-0.7)$ & $-9.2(-13.5 ;-4.9)$ \\
\hline Income above 200 & Reference & Reference & Reference & Reference \\
\hline \multicolumn{5}{|l|}{ Younger refugees (age below 50) } \\
\hline 5 or less depending persons & $9.7(-0.5 ; 19.9)$ & $4.8(-5.5 ; 15.0)$ & $7.7(-2.3 ; 17.7)$ & $7.0(-2.0 ; 16.0)$ \\
\hline 6 or more & $-2.2(-9.5 ; 5.1)$ & $-3.5(-10.9 ; 3.8)$ & $-5.3(-12.5 ; 1.9)$ & $3.1(-3.3 ; 9.6)$ \\
\hline \multicolumn{5}{|c|}{ Older refugees (age of 50 or more) } \\
\hline 5 or less depending persons & $4.8(-1.5 ; 11.1)$ & $6.7(0.4 ; 13.0)$ & $4.0(-2.2 ; 10.2)$ & II.7 (6.1; I7.2) \\
\hline 6 or more & Reference & Reference & Reference & Reference \\
\hline \multicolumn{5}{|l|}{ Marital status } \\
\hline Other & $-4.0(-8.8 ; 0.8)$ & $-6.4(-11.2 ;-1.7)$ & $-8.0(-12.7 ;-3.4)$ & $-2.9(-7.1 ; 1.3)$ \\
\hline Married & Reference & Reference & Reference & Reference \\
\hline
\end{tabular}

lation. The most striking difference between diabetic patients and controls was their level of education. The most likely explanation is that this reflects the lower willingness of controls with lower education to participate in the study. However, the number of eligible controls who refused participation was not appropriately recorded to provide evidence for this assumption. Given the practical limitations, the sampling technique for controls appeared most appropriate and was successfully implemented in other studies [24].

In a Danish validation study of the WHOQOL-BREF the mean scores were considerably higher for all the domains in diabetic patients (between 70 and 76 points) as compared to our sample (23 to 52), but only slightly higher for controls ( 74 to 89 versus 70 to 76 ) with the exception of the environment domain, where the score in our sam- ple was much lower ( 80 vs. 36) [23]. In the Iranian study the scores for the diabetic patients were lower than in the Danish study ( 55 to 65 ) but still considerably higher than in our sample [13]. Still the largest difference between our data and other studies was for the environment domain.

\section{Conclusion}

Diabetic patients living in the Gaza strip camps have a poor HRQOL compared to non-diabetic controls living under the same conditions and diabetic patients surveyed in other studies. Higher age further reduces the HRQOL in diabetic patients without having an impact on controls. Diabetes has a greater impact on the HRQOL of females than on the HRQOL of males. Under the living conditions encountered in this study, poverty strongly reduced HRQOL, especially in younger participants and this effect did not differ for diabetic patients and controls. 


\section{Competing interests}

The author(s) declare that they have no competing interests.

\section{Authors' contributions}

AE planned and conducted the study and drafted the first version of the manuscript. RTM performed the statistical analysis and wrote the final version of the manuscript. UL and AK contributed to study design and conceptualization. All authors read and approved the final manuscript.

\section{Acknowledgements}

During preparation of the study AE was funded by an unrestricted educational grant provided by DAAD. There was no other external funding for the study. We would like to thank Juergen Breckenkamp for the help during the conceptual preparation of this study and the staff who helped in various stages of the data collection. We also thank Annette Maxwell and Reinhard Bornemann for their comments on a previous version of this manuscript.

\section{References}

I. Wild S, Roglic G, Green A, Sicree R, King H: Global prevalence of diabetes: estimates for the year 2000 and projections for 2030. Diabetes Care 2004, 27(5): $1047-1053$.

2. Zimmet P: The burden of type $\mathbf{2}$ diabetes: are we doing enough? Diabetes Metab 2003, 29(4 Pt 2):6S9-I8.

3. Coffey JT, Brandle M, Zhou H, Marriott D, Burke R, Tabaei BP, Engelgau MM, Kaplan RM, Herman WH: Valuing health-related quality of life in diabetes. Diabetes Care 2002, 25(I 2):2238-2243.

4. Redekop WK, Koopmanschap MA, Stolk RP, Rutten GE, Wolffenbuttel $\mathrm{BH}$, Niessen LW: Health-related quality of life and treatment satisfaction in Dutch patients with type 2 diabetes. Diabetes Care 2002, 25(3):458-463.

5. Rubin RR, Peyrot M: Quality of life and diabetes. Diabetes Metab Res $\operatorname{Rev} 1$ 1999, I5(3):205-218.

6. Smith DW: The population perspective on quality of life among Americans with diabetes. Qual Life Res 2004, I3(8): |39|-| 400

7. Vileikyte L, Leventhal H, Gonzalez JS, Peyrot M, Rubin RR, Ulbrecht JS, Garrow A, Waterman C, Cavanagh PR, Boulton AJ: Diabetic peripheral neuropathy and depressive symptoms: the association revisited. Diabetes Care 2005, 28( I 0):2378-2383.

8. Goodridge D, Trepman E, Embil JM: Health-Related Quality of Life in Diabetic Patients With Foot Ulcers: Literature Review. J Wound Ostomy Continence Nurs 2005, 32(6):368-377.

9. Lloyd A, Sawyer W, Hopkinson P: Impact of long-term complications on quality of life in patients with type 2 diabetes not using insulin. Value Health 2001, 4(5):392-400.

10. Garratt AM, Schmidt L, Fitzpatrick R: Patient-assessed health outcome measures for diabetes: a structured review. Diabet Med 2002, I 9(I): I- I I.

II. Ghanbari A, Yekta ZP, Roushan ZA, Lakeh NM: Assessment of factors affecting quality of life in diabetic patients in Iran. Public Health Nurs 2005, 22(4):31 I-322.

12. Savli $H$, Sevinc A: The evaluation of the Turkish version of the Well-being Questionnaire (WBQ-22) in patients with Type 2 diabetes: the effects of diabetic complications. I Endocrinol Invest 2005, 28(8):683-69l.

13. Aghamollaei T, Eftekhar H, Shojaeizadeh D, Mohammad K, Nakhjavani M, Ghofrani Pour F: Behavior, Metabolic Control and Health-related Quality of Life in Diabetic Patients at Bandar Abbas Diabetic Clinic. Iranian J publ Health 2003, 32(3):54-59.

14. Aghamolaei T, Eftekhar H, Mohammad K, Nakhjavani M, Shojaeizadeh D, Ghofranipour F, Safa O: Effects of a health education program on behavior, Hba I c and health-related quality of life in diabetic patients. Acta Medica Iranica 2005, 43(2):89-94.

15. The United Nations Relief and Works Agency for Palestine Refugees in the Near East: Publications/Statistics: Total Registered Refugees per Country and Area [article online]. [http:// www.un.org/unrwa/publications/statis-0l.html].
16. Abdul-Rahim HF, Husseini A, Bjertness E, Giacaman R, Gordon NH, Jervell J: The metabolic syndrome in the West Bank population: an urban-rural comparison. Diabetes Care 2001, 24(2):275-279.

17. MOH-PHIC (Ed.): Health Status in Palestine 2003, Non-Communicable Diseases. Gaza, Palestine, Al-Remal Clinic Printing Office; 2004:75-9l.

18. Development of the World Health Organization WHOQOL-BREF quality of life assessment. The WHOQOL Group. Psychol Med 1998, 28(3):55।-558.

19. Sartorius NA: WHO method for the assessment of healthrelated quality of life (WHOQOL). In Quality of Life Assessment: Key Issues in the 1990s Edited by: Walker SR, Rosser RM. Dordrecht , Kluwer Academic Publishers ; 1993:201-207.

20. World Health Organization: WHOQOL-BREF: Introduction, Administration, scoring and generic version of the assessment. Field Trial Version (1996). Programme on Mental Health, WHO, Geneva, Switzerland. [article online]. [http:/ /www.who.int/mental health/media/en/76.pdf].

21. Hosmer DW, Lemeshow S: Applied logistic regression. In Wiley series in probability and statistics: texts and reference section 2nd edition. New York, Wiley-Interscience; 2000:373.

22. Hanestad BR, Rustoen T, Knudsen O Jr., Lerdal A, Wahl AK: Psychometric properties of the WHOQOL-BREF questionnaire for the Norwegian general population. J Nurs Meas 2004, I 2(2): | 47-I59.

23. Norholm V, Bech P: The WHO Quality of Life (WHOQOL) Questionnaire: Danish validation study. Nord J Psychiatry 200I, 55(4):229-235.

24. Lopes CS, Rodrigues LC, Sichieri R: The lack of selection bias in a snowball sampled case-control study on drug abuse. Int J Epidemiol 1996, 25(6): I 267-I270.

\section{Pre-publication history}

The pre-publication history for this paper can be accessed here:

\section{http://www.biomedcentral.com/1471-2458/6/268/pre} pub
Publish with Biomed Central and every scientist can read your work free of charge

"BioMed Central will be the most significant development for disseminating the results of biomedical research in our lifetime. "

Sir Paul Nurse, Cancer Research UK

Your research papers will be:

- available free of charge to the entire biomedical community

- peer reviewed and published immediately upon acceptance

- cited in PubMed and archived on PubMed Central

- yours - you keep the copyright
BiolMedcentral 